\title{
PENERAPAN HORTIKULTURA TERAPI UNTUK MENINGKATKAN SELF-EFFICACY PADA LANSIA
}

\author{
Aris Nugraha Silitonga, Monty P. Satiadarma, Widya Risnawaty \\ Fakultas Psikologi, Universitas Tarumanagara Jakarta \\ Email: aris_nugraha838@yahoo.com \\ Fakultas Psikologi, Universitas Tarumanagara Jakarta \\ Email: monty_satiadarma@yahoo.com \\ Fakultas Psikologi, Universitas Tarumanagara Jakarta \\ Email: widyar@fpsi.untar.ac.id
}

\begin{abstract}
ABSTRAK
Penelitian ini bertujuan untuk melihat penerapan hortikultura guna meningkatkan self-efficacy pada lansia di panti werdha Y. Lansia merupakan orang dewasa yang telah memasuki umur 60 tahun ke atas. Lansia yang berdaya merupakan lansia yang aktif dalam beraktivitas. Aktivitas yang dapat dilakukan oleh lansia sangatlah beragam. Salah satunya adalah kegiatan bercocok tanam. Kegiatan bercocok tanam yang dilakukan adalah kegiatan menanam kangkung. Partisipan penelitian ini berjumlah tiga orang lansia berusia lebih dari 60 tahun yang berada di Panti Werdha Y. Namun karena pengaruh kesehatan yang memburuk hanya menyisakan dua partisipan. Pengukuran dengan MMSE dan wawancara dilakukan dalam pengambilan data. Hsil penelitian menunjukkan bahwa self-efficacy sesudah melakukan kegiatan hortikultura meningkat.
\end{abstract}

Kata kunci: terapi hortikultura, self-efficacy, lansia, panti werdha

\section{PENDAHULUAN}

\section{Latar Belakang}

Hortikultura merupakan salah satu kegiatan bercocok tanam yang menggunakan media tanaman dengan tujuan yang bermacam-macam. Hortikultura dapat dilaksanakan sebagai suatu program terapi bagi individu. Hortikultura terapi adalah salah satu teknik intervensi yang menggunakan media tanaman, aktivitas berkebun dan kedekatan terhadap alam yang digunakan sebagai program terapi dan rehabilitasi (Davis, 1994). Menurut Haller dalam Simson dan Straus (1998) bahwa pelaksanaan hortikultura terapi dapat dilakukan di beberapa setting tempat, seperti sekolah, industri, greenhouse, rumah sakit, penjara atau panti sosial.

Manfaat hortikultura telah dilaporkan oleh Bortz dan Gal (dalam Fetherman, 2004) dalam studi yang telah dikembangkannya, yaitu meningkatkan perilaku mototrik, coping terhadap keberhasilan atau kegagalan, meningkatkan kemampuan sosial dalam kelompok, berkomitmen dan bertanggung jawab, membangun self-esteem, meningkatkan kemampuan kognitif, sebagai self-expression dan kreativitas, kesempatan untuk keluar (outdoor), memiliki aktivitas, dan sebagai rekreasi. Penerapan hortikultura dapat dilaksanakan pada berbagai macam tempat, seperti rumah sakit, institusi psikiatri, panti sosial, tempat rehabilitasi dan sekolah. Orang yang memiliki disabilitas secara fisik maupun mental, lanjut usia, orang dengan ketergantungan zat serta penyimpangan sosial dapat diberikan.

Sarana terapi seperti ini kiranya dapat dimanfaatkan di panti werdha, mengingat panti werdha di Indonesia masih memiliki keterbatasan kegiatan. Yuwanto (2011) menjelaskan bahwa panti werdha di Indonesia masih memiliki kendala terutama pada kegiatan dan aktivitas yang diberikan kepada lansia. Aktivitas dan kegiatan yang diberikan sangatlah terbatas yang menyebabkan timbulnya masalah-masalah lainnya. Padahal, perhatian dan kebutuhan terhadap lansia semakin hari semakin dibutuhkan. Kebutuhan dan perhatian terhadap lansia dapat 
disebabkan karena adanya penurunan fisik, mental dan sosial. Levy (2014) menyatakan bahwa penurunan fisik, mental dan sosial dapat mengarahkan lansia untuk menjadi tidak yakin terhadap kemampuannya sendiri. Akibatnya, lansia menjadi cenderung menolak karena merasa kurang mampu menjalankan tugas yang diberikan. Ariyani (2014) menambahkan bahwa minimnya kegiatan dan aktivitas yang dilakukan oleh pihak panti werdha menyebabkan para lansia menjadi bermalas-malasan dan tidak ingin melakukan aktivitas apapun.

Menurut Humboldt dan Leal (2014) menuturkan bahwa lansia akan ditantang terhadap perubahan fisik, mental dan sosial. Perubahan-perubahan inilah yang membawa lansia menjadi tidak berdaya dan merasa tidak berguna seperti saat masih muda dulu. Hal ini menurut Govindan (1999) mengarahkan lansia untuk menghindari tugas-tugas serta menolak untuk menyelesaikan tugas yang diberikan. Penurunan secara fisik dan mental menjadi faktor yang paling berperan dalam menghindari tugas-tugas yang diberikan. Lansia yang menghindari tugas ini mengarahkan pada menurunnya kepercayaan diri terhadap diri sendiri.

Feldman dalam Edginton, DeGraaf, Dieser, \& Edginton (2006), kecenderungan lansia untuk menghindari tugas-tugas yang diberikan serta adanya penurunan kepercayaan diri akan ditandai dengan adanya penarikan diri dari lingkungan sekitar. Penarikan diri dari lingkungan sekitar menyebabkan individu mencoba untuk menghindari kontak sosial dan melepaskan ikatan emosional dengan dunia sekitarnya. Penarikan diri ini juga akan menyebabkan lansia untuk tidak terlibat aktif dalam beraktivitas. Padahal, menurut Feldman, proses penuaan yang sukses ketika lansia mampu mempertahankan kegiatan dan interaksi sosial di lingkungannya. Lanisa akan tetap aktif dan produktif meskipun secara fisik maupun kognitif, lansia telah mengalami penurunan. Hal ini akan mengarahkan lansia untuk tetap berdaya (Edginton, et. al., 2006).

Menurut Albert Bandura (1977), keyakinan seseorang dalam menyelesaikan suatu tugas disebut dengan self-efficacy. Orang dengan self-efficacy yang tinggi akan dengan berani menghadapi masalah yang dimiliki daripada menghindari masalah tersebut. Di lingkungan sosial, persepsi masyarakat terhadap lansia akan mengarahkan pada perubahan nilai-nilai bagi lansia. Lansia akan cenderung kurang dianggap dan diperhatikan sebagai orang yang telah berpengaruh di dalam kehidupan masyarakat. Kesadaran inilah perlu ditingkatkan oleh masyarakat agar lansia tetap dapat diterima di lingkungan sosial (Perkins, Multhaup, Perkins, \& Barton, 2008).

Di sisi lain, tantangan hidup keluarga terus bertambah dan peluang keluarga untuk secara langsung membantu para orang tua mereka kian terbatas. Keberadaan panti werdha akan banyak membantu keluarga dalam menangani orang tua mereka. Namun, panti werdha perlu mengembangkan kegiatan yang layak dan sesuai dengan kondisi para lansia. Mariani dan Kadir (2013) menuturkan bahwa program-program pelayanan sosial akan membantu lansia dalam mengisi waktu luang seperti bimbingan mental dan spiritual, rekreasi, penyaluran hobi dan bakat, senam dan bercocok tanam. Adanya kegiatan dan aktivitas yang tepat di panti werdha akan membantu lansia untuk menjalani kesehariannya dengan baik (Ariyani, 2014).

Pada lansia, hortikultura terapi memberikan kesempatan bagi lansia untuk melatih dan menjaga kemampuan motorik, seperti koordinasi mata dan tangan, melatih otot-otot serta memberikan latihan ringan. Program hortikultura terapi juga membantu lansia untuk meningkatkan kepercayaan diri serta memunculkan rasa puas ketika tanaman yang mereka tanam dapat tumbuh. Dengan hortikultura terapi, lansia akan diajak untuk lebih mampu mengontrol hidupnya serta memberikan tujuan dalam kegiatan sehari-hari (Haller \& Kramer, 2006). Rasa kepercayaan 
diri pada lansia akan membantu mereka untuk menerima serta berusaha menyelesaikan tugastugas yang diberikan.

Hasil penelitian Judie dan Vijayalakshmi (2016) menunjukkan bahwa hortikultura terapi terbukti efektif dalam menurunkan tingkat depresi pada orang lansia yang tinggal di institusi. Hal senada juga dijelaskan oleh Rappe (2005) bahwa aktivitas hortikultura juga mampu meningkatkan wellbeing lansia, peningkatan kesehatan menurut penilaian individu sendiri, dan meningkatkan interaksi sosial dengan lingkungan sekitar. Rappe juga menambahkan aktivitas hortikultura mengajak lansia untuk mengekspresikan diri sendiri bahwa mereka memiliki kemampuan dan kapabilitas dalam melaksanakan sesuatu yang mendukung identitas dan otonomi mereka. Berdasarkan penelitian lainnya dari Gibson dan Hughes (2000) ditemukan bahwa self-esteem dan self-efficacy meningkat ketika orang berpartisipasi dalam program hortikultura.

Berdasarkan hasil uraian-uraian di atas, hortikultura dapat digunakan sebagai salah satu bentuk alternatif terapi lain yang tepat dan cocok bagi lansia. Tujuannya adalah guna memberdayakan para lansia yang tinggal di panti werdha dengan aktivitas bercocok tanam. Peneliti ingin mengangkat topik hortikultura sebagai salah satu teknik terapeutik yang dapat digunakan pada lansia di panti werdha. Penerapan hortikultura ini diharapkan dapat menjadi salah satu bentuk teknik intervensi untuk meningkatkan self-efficacy pada lansia di panti werdha.

Berdasarkan pemikiran di atas, rumusan masalah dalam penelitian ini adalah bagaimana penerapan hortikultura untuk meningkatkan self-efficacy pada lansia di panti werdha Y? Penelitian ini bertujuan mengkaji penerapan dari hortikultura dalam upaya meningkatkan selfefficacy pada lansia di panti werdha Y.

\section{METODE PENELITIAN}

\section{Partisipan}

Kriteria partisipan dalam penelitian ini adalah para lansia yang berusia 60 tahun ke atas dan sedang berada di panti werdha Y Jakarta. Cara yang digunakan untuk menentukan lansia adalah dengan wawancara, MMSE dan kuesioner. Target jumlah partisipan dalam penelitian ini adalah para lansia yang saat ini bersedia untuk berpartisipasi, sedang tinggal di panti werdha Y Jakarta selama satu tahun, tidak memiliki masalah kognitif atau demensia dan memiliki masalah dengan self-efficacy.

Pedoman wawancara dilakukan untuk melihat latarbelakang partisipan yang mengikuti kegiatan. MMSE diberikan untuk melihat apakah partisipan yang terlibat memiliki gangguan kognitif ataupun permasalahan demensia. Menurut Kurlowicz dan Wallace (1999), MMSE merupakan salah satu cara untuk menentukan seseorang memiliki gangguan kognisi. Jumlah skor minimum untuk memenuhi kriteria MMSE adalah 23. Pemberian kuesioner dilakukan untuk melihat apakah partisipan yang mengikuti benar-benar memiliki masalah terhadap self-efficacy atau tidak.

\section{Desain Penelitian}

Desain penelitian yang digunakan adalah one-group pretest-postest design. Desain ini dilakukan pengukuran terhadap self-effiacy pada lansia di panti werdha Y dengan menggunakan alat ukur berupa kuesioner yang mengukur variabel self-efficacy. Setelah partisipan diberikan intervensi berupa hortikultura maka dilakukan pengukuran kembali terhadap self-efficacy pada lansia dengan menggunakan alat ukur yang sama. 


\section{Setting Lokasi dan Perlengkapan Penelitian}

Penelitian ini dilakukan pada salah satu panti werdha di Jakarta dengan menggunakan ruangan aula dari panti tersebut. Alat-alat yang digunakan dalam penelitian ini adalah kuesioner, kertas, pensil, penghapus dan pulpen. Dalam penelitian ini, kuesioner yang digunakan adalah General Self-efficacy Scale (GSES) milik Schwarzer (1995) yang telah diterjemahkan ke Bahasa Indonesia. Alat ukur GSES disarankan untuk digunakan pada individu yang telah memasuki tahapan dewasa. Alat ukur GSES digunakan untuk melihat kemampuan pemecahan masalah, motivasi dalam melaksanakan tujuan, keyakinan dalam menjalankan tugas yang sulit, memiliki tujuan serta keyakinan untuk dapat kembali ketika mengalami kegagalan.

\section{Pengukuran}

Alat ukur dalam penelitian ini adalah General self-efficacy scale (GSES) yang telah diadaptasi dan diterjemahkan ke Bahasa Indonesia oleh Aristi Born, Ralf Schwarzer dan Matthias Jerusalem pada tahun 1995. Kuesioner ini akan memiliki empat poin penilaian yang mana poin pertama menyatakan untuk pernyataan yang tidak setuju, poin kedua menyatakan pernyataan yang agak setuju, poin ketiga untuk pernyataan hampir setuju, dan poin keempat untuk pernyataan yang sangat setuju.

Berdasarkan hasil uji reliabilitas yang dilakukan oleh Born, Schwarzer, dan Jerusalem (1995) ditemukan bahwa skala Schwarzer memiliki nilai reliabilitas sebesar 0,75-0,91. Pada alat ukur ini tidak memiliki butir positif maupun negatif. Menurut Schwarzer dan Jerusalem (1992) mengatakan bahwa penilaian dilakukan dengan cara melakukan jumlah skor dengan kriteria minimum sebesar 30 poin.

\section{HASIL DAN PEMBAHASAN}

\section{Analisis dan Hasil Intervensi}

Hasil analisis menunjukkan bahwa adanya peningkatan self-efficacy pada masing-masing partisipan. Pada partisipan PA, self-efficacy sebelum mengikuti intervensi adalah 2.40, kemudian setelah mengikuti intervensi self-efficacy PA adalah 3.10. Kemudian pada partisipan LY, nilai rata-rata self-efficacy LY adalah 1.80 dan setelah mengikuti kegiatan hortikultura, nilai rata-rata self-efficacy LY menjadi 2.30. Ini menunjukkan bahwa kedua partisipan lebih yakin untuk menjalankan tugas yang diberikan, mampu menghadapi situasi-situasi yang kurang mendukung serta menemukan solusi atas permasalahan yang terjadi pada kehidupan sehari-hari. Tabel 1 menunjukkan gambaran tingkat self-efficacy sebelum dan sesudah pelaksanaan Program Terapi Hortikultura.

Tabel 1. Gambaran Rata-rata Tingkat Self-efficacy Sebelum dan Sesudah Mengikuti Program Hortikultura Terapi

\begin{tabular}{ccccc}
\hline & Pretest PA & Posttest PA & Pretest LY & Posttest LY \\
\hline Self-efficacy & 2.40 & 3.10 & 1.80 & 2.30 \\
\hline
\end{tabular}

Perubahan self-efficacy dimulai sejak sesi pertama yang mana peneliti mengajak partisipan untuk mengikuti kegiatan bercocok tanam. Hal ini berarti bahwa adanya social persuasion yang merupakan salah satu karakteristik dari self efficacy. Social persuasion dari peneliti mengajak partisipan agar mau terlibat dalam kegiatan. Lalu, pada sesi kedua partisipan mulai mempraktekkan kemampuan dan pemahaman yang telah dipelajari. Hal ini menunjukkan mulai dibentuknya mastery experiences melalui bercocok tanam kangkung. Pertumbuhan tanaman 
kangkung yang dimulai dari kemunculan tunas, batang yang membesar, daun-daun yang melebar serta pertambahan tinggi dari tanaman kangkung memberikan pengalaman baru (mastery experiences) dalam peningkatan self-efficacy yang terjadi pada kedua partisipan.

\section{KESIMPULAN DAN SARAN}

\section{Kesimpulan}

Berdasarkan hasil intervensi hortikultura yang dijalani oleh kedua subyek maka dapat disimpulkan bahwa intervensi hortikultura dapat meningkatkan self-efficacy pada lansia. Hal ini didasarkan pada adanya peningkatan nilai rata-rata self-efficacy pada masing-masing partisipan. Dengan demikian, hortikultura terapi dapat meningkatkan self-efficacy melalui karakteristik mastery experiences dan social persuasion.

Sumber self-efficacy yang terjadi pertama kali adalah social persuasion. Kedua partisipan diajak untuk mengikuti kegiatan hortikultura terapi yang mana kedua partisipan memiliki rasa ingin tahu terhadap kegiatan hortikultura. Partisipan juga ingin mencoba pengalaman baru karena semasa kecil hingga dewasa partisipan belum pernah melakukan kegiatan hortikultura.

Pada sesi kedua hingga akhir, kedua partisipan mulai mendapatkan pengalaman langsung yang mana menjadi sumber self-efficacy, yaitu mastery experiences melalui kegiatan hortikultura. Partisipan memulai bercocoktanam disertai dengan munculnya perasaan senang dan bahagia ketika melihat tanamannya yang mulai tumbuh. Kemudian, partisipan juga memiliki rasa ingin tahu serta tujuan di hari esok karena keingintahuannya untuk melihat pertumbuhan tanamannya. Selain itu, partisipan juga menjadi lebih bertanggungjawab, mampu menyelesaikan masalah serta dapat menerima keadaan ketika tanamannya yang belum tumbuh sempurna.

\section{Saran Untuk Partisipan Penelitian}

Saran bagi PA adalah untuk tetap melanjutkan tugasnya dalam menyiram tanaman. Hal ini dikarenakan pertumbuhan tanaman yang masih belum sempurna serta adanya kemungkinan bagi tanaman sayur yang ditanam untuk tumbuh lebih baik lagi. PA juga dapat memantau perubahan yang terjadi pada tanaman kangkung yang ditanam. Hal ini dapat disebabkan berbagai faktor sehingga tanaman yang ditanam tumbuh kurang begitu sempurna. Jika nanti PA telah berhasil menanam kangkung dan ia tertarik untuk menanam cabai seperti yang ia kemukakan, maka PA dapat diberikan kesempatan untuk mencobakan tentunya dengan bantuan dan pengaasan bimbingan terapis mengingat hal ini merupakan salah satu dari program terapeutik.

Saran untuk LY adalah tetap melanjutkan rutinitas dan aktivitas menyiram tanaman seperti yang ia lakukan karena pertumbuhan tanaman yang masih belum sempurna. LY mungkin belum merasakan perubahan dari segi fisik karena merasa dirinya sehat namun dari aspek psikologis, LY terlihat bertanggung jawab dan lebih aktif untuk keluar dari kamar dan adanya interaksi dengan lingkungan sekitar, seperti petugas dan penghuni panti lainnya. LY dapat mulai mencobakan diri untuk mengikuti kegiatan dengan mengikuti kegiatan bersama temannya.

\section{Saran untuk penelitian selanjutnya}

Bagi peneliti yang ingin menerapkan hortikultura sebagai bentuk intervensi dapat memperhatikan jenis tanaman, lama pertumbuhan tanaman, serta kemampuan dari terapis agar penerapan intervensi hortikultura dapat dilakukan dan berhasil. Jenis tanaman dapat berpengaruh pada durasi pertumbuhan tanaman serta kecocokan dengan musim yang terjadi di Indonesia. Kemudian, lama pertumbuhan tanaman akan berpengaruh pada efektivitas intervensi hortikultura 
pada partisipan. Selain itu, diperlukannya untuk melakukan pemilahan pada benih yang ingin ditanam. Hal ini dikarenakan adanya kemungkinan benih yang kurang baik akan ikut ditanam ketika kegiatan hortikultura berlangsung. Kemampuan dari terapis juga mempengaruhi akan keberhasilan dalam proses menanam.

Penelitian lain juga dapat mempertimbangkan aspek lain, seperti aktivitas fisik yang tercapai dari kegiatan hortikultura (dapat diukur melalui,tekanan darah), perkembangan emosi dari partisipan, interaksi partisipan terhadap tanaman dan lingkungan sekitar serta peneliti juga dapat mempertimbangkan variabel-variabel lain untuk diukur, seperti self-esteem karena lansia dengan self-esteem yang tinggi akan membantu lansia menjadi lebih berdaya.

Penelitian selanjutnya dapat memperhatikan jumlah sesi yang diberikan. Jumlah sesi dapat disesuaikan dengan jenis tanaman serta lama pertumbuhan dari tanaman. Semakin lama pertumbuhan dari tanaman bukan tidak mungkin akan lebih baik. Jumlah subyek dalam penelitian selanjutnya perlu ditambah. Hal ini dikarenakan semakin banyak jumlah subyek maka semakin bervariasi pula hasil yang akan diperoleh sehingga akan aspek-aspek psikologis lain yang tampak dapat diobservasi dalam proses terapi dan dapat dijadikan bahas diskusi pada hasil penelitian.

\section{Acknowledgement}

Terima kasih penulis ucapkan kepada pengelola Panti Werdha Y yang telah memberikan kesempatan bagi penulis untuk melaksanakan penelitian. Penulis juga menyampaikan terima kasih kepada Program Studi Magister Psikologi Universitas Tarumanagara yang telah memfasilitasi penelitian ini.

\section{REFERENSI}

Allison, M. J. \& Keller, C. (2004). Self-efficacy intervention effects on physical activity in older adults. Western journal of nursing research, 26(1), 31-46.

Bandura, A. (1977). Self-efficacy: Toward a unifying theory of behavioral change. Psychological review, 84 (2), 191-215.

Barnicle T. \& Midden, K. S. (2003). The effects of a horticulture activity program on the psychological well-being of older people in a long-term care facility. Hort Technology, 13(1), 81-85.

Daubert, J. R. \& Rothert, E. (1981). Horticultural therapy series. Horticultural therapy services, Chicago Horticultural Society.

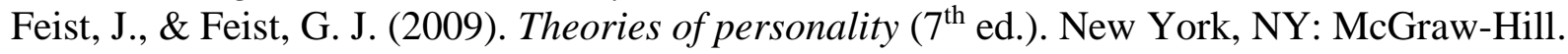

Gibson, R. B. \& Hughes, M. P. (2000). Treatment of the sexually violent predator: A horticultural approach. Journal of therapeutic horticulture, 11.

Govindan, A. (1999). Self-efficacy and depression in older adults: Differences between volunteers and non-volunteers. Theses: Doctorates and Masters.

Haller, R. L. \& Kramer, C. L. (2006). Horticultural therapy methods: Making connections in health care, human service and community programs. United States, US: Taylor and Francis Group.

Hefley, P. D. (1973). Horticulture: A therapeutic tool. Journal of rehabilitation.

Humboldt, S. \& Leal, I. (2014). Adjustment to aging in late adulthood: A systematic review. International journal of gerontology, 8, 108-113.

Kaplan, R. (1973). Some psychological benefits of gardening. Environmental behavior, 5(2), 145-162. 
Kaplan, S. (1992) in Relf, D (eds.). The role of horticulture in human well-being and social development. Portland, OR: Timber Press.

King, L. A. (2011). The science of psychology: an appreciative view ( $2^{\text {nd }}$ ed.). New York: McGraw-Hill.

McAuley, E. \& Blissmer, B. (2000). Self-efficacy determinants and consequences of physical activity. Journal of exercise and sports reviews, 28(2), 85-88.

Miller, P. H. (2011). Theories of developmental psychology ( $5^{\text {th }}$ ed.). New York, NY: Worth Publisher.

Myers, D. G. (2010). Social psychology (10 ${ }^{\text {th }}$ ed.). New York: McGraw-Hill.

Papalia, D., Olds, S. M., \& Feldman, R. D. (2009). Human development. (11 $1^{\text {th }}$ ed.). New York: McGraw-Hill.

Perkins, J. M., Multhaup, K. S., Perkins, H. W., \& Barton C. (2008). Self-efficacy and participation in physical and social activity among older adults in Spain and United States. The Gerontologist, 48(1), 51-58.

Rothert, E. A. \& Daubert, J. R. (1981). Horticultural therapy at a physical rehabilitation facility. Chicago: Chicago horticultural society.

Setyoadji, D. (2016). Asiknya bercocok tanam sayuran polybag dan tabulampot: Cara sederhana menikmati sayuran dan buah berkualitas. Yogyakarta: Arashka Publisher.

Simson S. P. \& Straus, W. C. (1998). Horticulture as therapy: Principles and practice. United States, US: CRC Press.

Susanto, I., \& Wirawan, H. E. (2008). Gambaran self efficacy orangtua anak autisme. Arkhe Jurnal Psikologi, 13(2), 98-115.

Seniati, L., Yulianto, A., \& Setiadi, B. N. (2008). Psikologi eksperimen. Jakarta: PT. Tunas Jaya Lestari.

Weiten, W. \& Lloyd, M. A. (2006). Psychology applied to modern life: Adjustment in $21^{\text {st }}$ Century. Boston: Cengage Learning. 